\title{
Cambio curricular universitario: aportes para el debate
}

\author{
Susana Marcipar Katz \\ Prof. Titular Matemática Básica - \\ FCE,UNL \\ Email:susmarci@fce.unl.edu.ar
}

\section{Resumen}

El presente trabajo pretende delinear de manera sencilla la complejidad del proceso inherente al diseño de un currículo universitario para que sirva como un primer documento que oriente y estimule al debate sobre dicho tema.

Esta dirigido a una comunidad educativa cuyos integrantes poseen diversas formaciones y capacidades que suelen ser diferentes de las que un experto en educación despliega al momento de opinar sobre «diseño de currículo». Por ello, se utiliza un lenguaje llano y accesible sin dejar de ser preciso y técnico, inclusive se han incorporado metáforas como recurso literario para lograr mayor comprensión de los diferentes conceptos involucrados. No contiene citas de otros autores pero se ha incluido, al final, bibliografía recomendada para quienes deseen ampliar sobre el tema.

El trabajo contiene cuatro partes. En la primera, bajo el título «consideraciones preliminares» se explica la diferencia que existe entre el currículo escrito y aprobado oportunamente por los órganos correspondientes y el que efectivamente se desarrolla.

En un segundo ítem, titulado «componentes principales de un currículo escrito» se consideran algunos de los conceptos que se constituyen en núcleos o nudos fundamentales de un currículo universitario.

En tercer lugar se describe un camino posible para lograr el cambio curricular deseado. Así, se proponen cuatro etapas con seis instancias cada una. Además, se ha diseñado un cuadro sintetizando el proceso propuesto incorporándose algunas acciones 0 actividades, a modo de ejemplo, para las dos primeras etapas.

Por último, «a modo de reflexión final» se reconoce la complejidad y esfuerzo institucional al emprenderse un cambio curricular pero asimismo se explicita la riqueza y crecimiento que brinda dicho proceso. 